\title{
Histology of spheroidal degeneration of the cornea in Labrador
}

\author{
GORDON J. JOHNSON AND MARY OVERALL \\ From the International Grenfell Association and the Nuffield Laboratory of Ophthalmology, Oxford
}

SUMMARY Nine specimens of the corneas of patients from Labrador and Northern Newfoundland affected by spheroidal degeneration (climatic droplet keratopathy) have been examined microscopically. Histochemical stains confirmed studies of similar corneal degenerations from other geographical areas that the droplets contain a protein which does not have all the characteristic properties of elastic tissue. Staining compatible in some instances with fibrin and 'fibrinoid' was found. By immunoperoxidase techniques the droplets were located in the zones of greatest concentration of various plasma constituents, especially albumin and immunoglobulins $G$ and $A$. Reasons are given why the abnormal deposits are not thought to be derived directly from corneal collagen.

It is suggested that some of the plasma proteins, which are known to be diffusing through the cornea from the limbal vessels under normal conditions, are acted upon by the ultraviolet light reflected from the ice of Labrador and degraded so that they accumulate in the superficial stroma.

There is current interest in a type of degeneration of the cornea which is now termed either droplet keratopathy (Freedman, 1973a) or spheroid (spheroidal) degeneration (Fraunfelder et al., 1972). Spheroidal or nodular deposits of abnormal hyaline material accumulate in Bowman's layer and the superficial stroma. At least 12 English-language papers have described the light or electron microscopy of this condition. They included material from regions where external climatic factors appeared to be the main aetiological agent (Klintworth, 1972; D'Alena and Wood, 1972; Garner et al., 1973; Johnson and Ghosh, 1975), cases from temperate regions where no definite aetiology was proposed (Etzine and Kaufmann, 1964; Christensen, 1973; Garner et al., 1976), and cases of spheroidal degeneration in association with a corneal dystrophy (Garner, 1970), and in association with other intraocular disease and trauma (Hanna and Fraunfelder, 1972; Brownstein et al., 1973; Rodrigues et al., 1975; Cursino and Fine, 1976).

Analysis of all the staining reactions reported shows a good general agreement between authors, who used tissue from different sources. Within the spheroidal bodies there is a protein, containing a considerable proportion of the amino-acids trypto-

Address for reprints: Dr G. J. Johnson, International Grenfell Association, St. Anthony, Newfoundland AOK 4SO, Canada phan, tyrosine, cysteine, and cystine, which are not normally present in the corneal stroma in large amounts. The deposits also have some of the staining properties of ribonucleic acid. At one time the protein was thought to be related to keratin and was labelled 'keratinoid' (Garner, 1970). The most popular terms at present are 'elastotic degeneration' or 'elastosis', but Garner et al. (1976) have now shown that the deposits do not stain with 2 of the characteristic stains for elastic tissue. The precise chemical identity of the material has therefore not yet been determined. Most authors imply that it is formed in situ from structural components of the cornea. Klintworth (1972), however, proposed that degenerate elastotic material formed from collagen beneath the adjacent conjunctiva might be diffusing into the cornea.

The form of droplet keratopathy, or spheroidal degeneration, seen with such remarkable frequency in the people of Northern Newfoundland and Labrador was originally described in a classic paper by Freedman (1965) under the title 'Labrador Keratopathy'. Additional details of the clinical features and prevalence in that geographical area may be found in the reports by Gillan (1970), Freedman (1973a, 1973b), Wyatt (1973), Johnson and Ghosh (1975), and Young and Finlay (1975).

The electron microscopy of specimens from Northern Newfoundland and Labrador has already 
Table 1 Details of patients from which specimens obtained

\begin{tabular}{|c|c|c|c|c|c|c|}
\hline $\begin{array}{l}\text { Case } \\
\text { no. }\end{array}$ & Race & Age & Sex & $\begin{array}{l}\text { Grade of } \\
\text { kerato- } \\
\text { pathy }\end{array}$ & $\begin{array}{l}\text { Source of } \\
\text { specimen }\end{array}$ & $\begin{array}{l}\text { Associated } \\
\text { conditions }\end{array}$ \\
\hline 1 & Caucasian & 68 & $\mathbf{F}$ & 1 & Peripheral & $\begin{array}{l}\text { Cataract: } \\
\text { diabetes }\end{array}$ \\
\hline 2 & Caucasian & 58 & $\mathbf{M}$ & 1 & $\begin{array}{l}\text { Whole eyes (one } \\
\text { used as graft } \\
\text { donor) }\end{array}$ & - \\
\hline 3 & Caucasian & 62 & $\mathbf{M}$ & 1 & $\begin{array}{l}\text { Keratectomy } \\
\text { (central and } \\
\text { peripheral) }\end{array}$ & $\begin{array}{l}\text { Large } \\
\text { pterygia }\end{array}$ \\
\hline 4 & Caucasian & 64 & $\mathbf{M}$ & 2 & Peripheral & Cataract \\
\hline 5 & Caucasian & 72 & $\mathbf{M}$ & 3 & $\begin{array}{c}\text { Central lamellar } \\
\text { keratectomy }\end{array}$ & Cataract \\
\hline 6 & Caucasian & 77 & $\mathbf{M}$ & 3 & $\begin{array}{l}\text { Central and } \\
\text { peripheral }\end{array}$ & Cataract \\
\hline 7 & Caucasian & 81 & $\mathbf{M}$ & 3 & Peripheral & Cataract \\
\hline 8 & Eskimo & 61 & $\mathbf{M}$ & 2 & Peripheral & Cataract \\
\hline 9 & Eskimo & 86 & $\mathbf{M}$ & 3 & Peripheral & Cataract \\
\hline
\end{tabular}

been published (Johnson and Ghosh, 1975). This report describes additional histochemistry of corneal tissue from the same geographical region, and puts forward a new hypothesis for the origin of the material.

\section{Materials and methods}

The 9 patients from whom histological material came are listed in Table 1. The tissue was obtained by central lamellar keratectomy for visual indications, by keratectomy of a large pterygium or by superficial biopsy of peripheral cornea at the time of making a fornix-based flap as part of a cataract extraction. The tissue was fixed immediately in formol-saline and after transportation embedded in Paramat (Gurr). In addition, 2 whole eyes were donated for grafting, from 1 of which a lamellar button was cut, so that these eyes were fixed 12 hours after death.

Six control donor eyes were obtained in England. The anterior segments of 3 were fixed in absolute ethanol 3 parts to glacial acetic acid 1 part for 18 hours, the remainder in formol-saline. This control tissue was fixed 12 to 36 hours after death.

The pathological specimens were stained by the methods listed in Table 2 using standard techniques according to Pearse (1968) or Culling (1974). The stains for elastin, namely Verhoeff-van Gieson, orcein, Gomori's aldehyde fuchsin, and rhodanile blue (McConaill and Gurr, 1964) were controlled by staining the elastic fibres of sections of temporal artery. Specimens were also examined with the Zeiss fluorescence microscope for natural fluorescence as well as after staining with thioflavin $T$ using the BG 12 excitor filter with barrier filters 53 plus 44 .

In addition sections of both specimens and controls were tested by the antiperoxidase-peroxidase (PAP) method (Burns, 1975), using commercial unconjugated antihuman antibodies prepared in the rabbit against serum albumin, IgG, IgA, IgM, $\mathrm{C}_{3}$ complement, $\alpha-2$ macroglobulin, transferrin, and fibrinogen (DAKO-immunoglobulins). Since albumin or other adhesive was not used on the slides, many specimens washed away. Material was limited, and series of slides were obtained for 4 pathological corneas as well as 4 controls.

One specimen of formalin-fixed tissue (Case 5), originally embedded in Paramat, was dewaxed and

Table 2 Results of histochemical staining of spheroidal degeneration

\begin{tabular}{|c|c|c|}
\hline Stain & Cases tested & Staining of droplets \\
\hline $\begin{array}{l}\text { Haematoxylin and } \\
\text { eosin }\end{array}$ & $1,2,4,5$ & $\begin{array}{l}\text { Small droplets eosinophilic; } \\
\text { larger eosinophilic with } \\
\text { basophilic centres }\end{array}$ \\
\hline Periodic-acid-Schiff & 2,4 & Negative \\
\hline Toluidine blue & $1,2,4,5$ & Blue-green; no metachromasia \\
\hline Feulgen & 2,4 & Negative \\
\hline Methyl green-pyronin & 2,4 & $\begin{array}{l}\text { Bright red; no change after } \\
\text { RNA-ase }\end{array}$ \\
\hline $\begin{array}{l}\text { Gallocyanin- } \\
\text { chromalum }\end{array}$ & 2 & $\begin{array}{l}\text { Grey; no change after RNA- } \\
\text { ase }\end{array}$ \\
\hline Mallory's PTAH & $1-9$ & Purple (fibrinoid purple) \\
\hline Martius-scarlet-blue & $1-9$ & $\begin{array}{l}\text { All red or orange-brown } \\
\text { (fibrin red) }\end{array}$ \\
\hline Masson 44/41 & $\begin{array}{l}1,2,3,4,5,7 \\
\quad 8,9\end{array}$ & $\begin{array}{l}\text { Orange-brown (old fibrin } \\
\text { blue-black) }\end{array}$ \\
\hline Rhodanile blue & 2 & Purplish-pink (fibrin deep red) \\
\hline Verhoeff-van Gieson & $1,2,4,5$ & $\begin{array}{l}\text { Almost black, but browner } \\
\text { than blue-black of elastic } \\
\text { fibres; some olive-brown }\end{array}$ \\
\hline Orcein & $1,2,4,6,8,9$ & Negative (pale yellow) \\
\hline $\begin{array}{l}\text { Gomori's aldehyde } \\
\text { fuchsin }\end{array}$ & $1,2,6,8,9$ & $\begin{array}{l}\text { Variable pink, some colour- } \\
\text { less; elastic fibres very deep } \\
\text { pink; deep pink material } \\
\text { in pingueculum }\end{array}$ \\
\hline Fontana silver & $\begin{array}{l}1,2,3,5,6,7 \\
\quad 8,9\end{array}$ & Negative \\
\hline Congo Red & $1,2,4$ & Negative \\
\hline Thioflavin $\mathbf{T}$ & 5 & $\begin{array}{l}\text { Negative (fluorescence less } \\
\text { than natural fluorescence) }\end{array}$ \\
\hline
\end{tabular}


embedded in Araldite, without further fixation or staining, for electron microscopy.

\section{Results}

The staining reactions of the droplets are summarised in Table 2. The results were very similar in all specimens tested.

With methyl green pyronin the spheroids stained bright pink. This was not altered by pretreatment with RNA-ase for 2 hours. Similarly, the pale grey staining with gallocyanin chromalum was unaffected by RNA-ase. These reactions are therefore not consistent with the material being ribonucleic acid.

The Martius-scarlet-blue method stains fibrin red. The red or orange-brown reaction of the material in these droplets indicated a staining property in common with fibrin (Fig. 8).

The size and distribution of individual droplets were shown up particularly well by Mallory's phosphotungstic acid-haematoxylin method. At the extreme periphery, in the early stages of the keratopathy, there was characteristically a margin of cornea free of droplets (Fig. 1). The margin of the affected layer began abruptly with a dense accumulation of rather large spheroids. These became both smaller and sparser towards the centre of the cornea (Fig. 2). They were absent from the pupillary area in grade $I$. The deep purple of the droplets with this stain was suggestive of fibrinoid rather than of fibrin, which should appear a bright blue. In a more severe grade of keratopathy the periphery of the larger droplets stained darker than the centres

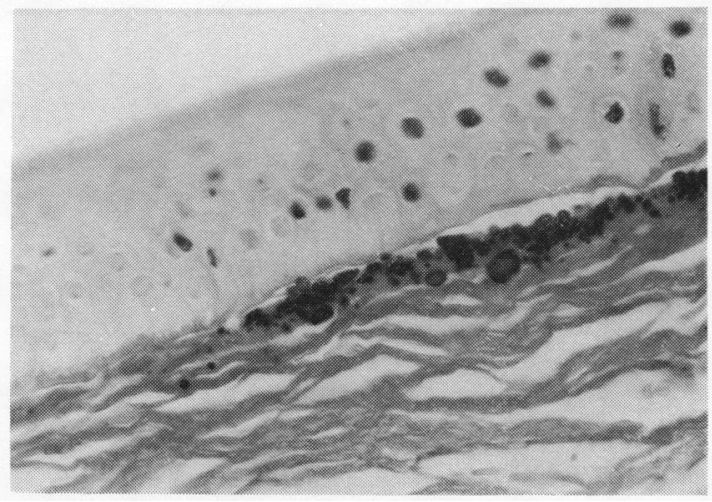

Figs. 1-4 Sections of corneas affected by spheroidal degeneration stained with phosphotungstic acid-haematoxylin. (Magnification of negative $\times 160$, of these prints $\times 300$ )

Fig. 1 Grade II (Case 8) to show abrupt appearance of droplets central to margin of cornea, leaving a clear marginal zone

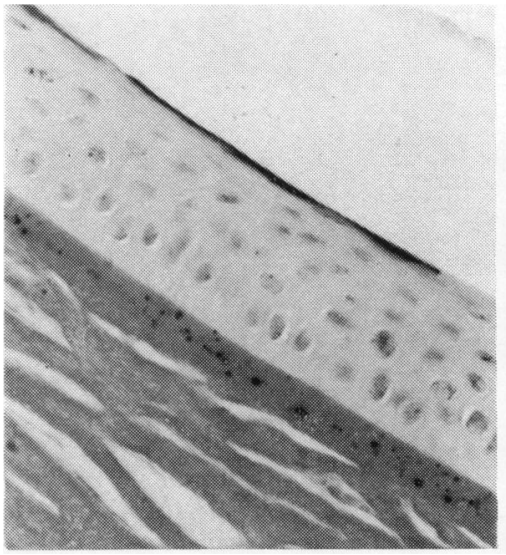

Fig. 2 Grade I (Case 2), further centrally but still in periphery of cornea, showing smaller droplets arranged sparsely in Bowman's layer

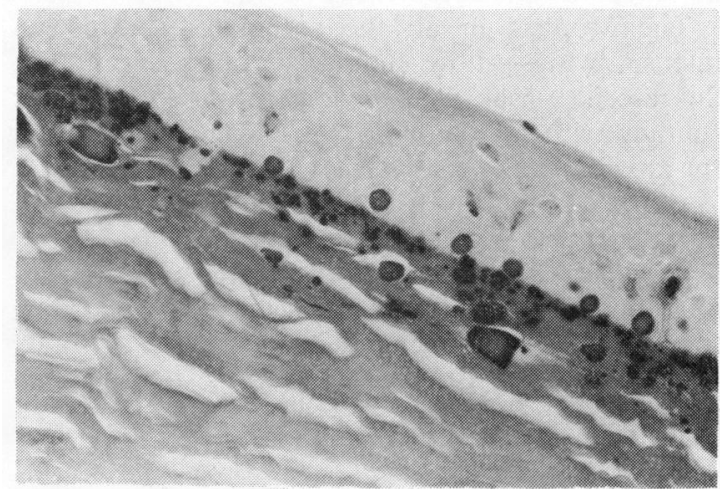

Fig. 3 Grade III (Case 6) to show larger, more irregular accumulations of abnormal material and some spheroidal bodies appearing to invade between basal epithelial cells

(Fig. 3). The smaller deposits stained uniformly across their diameter. Paler staining in the centre of the larger droplets was also a feature of staining by haematoxylin and eosin (Fig. 6).

One percent rhodanile blue, $\mathrm{pH} 7.0$ for 30 minutes (McConaill and Gurr, 1964) is said to stain fibrin deep red, elastic fibres blue, and collagen fibres colourless. The droplets in the 1 specimen so far tested were purplish-pink. The larger elastic fibres in the temporal artery were blue. The small elastic fibres which stain with Verhoeff, orcein, and aldehyde fuchsin were not stained with rhodanile blue.

The epithelium was normal in all cases except Case 9, a severe example of grade III keratopathy. In this specimen the epithelium was thinned to 2 or 3 layers of cells over the large irregular conglomerates 


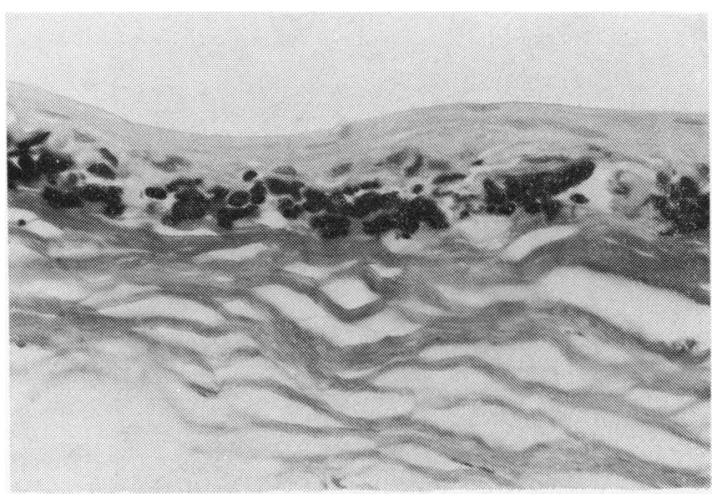

Fig. 4 Severe example of Grade III (Case 9) in which epithelium was thinned over irregular conglomerates of droplet material

of droplet material; Bowman's membrane was also destroyed in this specimen (Fig. 4).

The droplets in all the specimens showed an intense white-yellow natural fluorescence. The fluorescence was rather less pronounced after staining with thioflavin $T$. The Congo red reaction for amyloid was negative.

\section{IMMUNOPEROXIDASE METHOD}

The density of staining of the corneas by the immunoperoxidase method varied widely according to the plasma component against which the antibody was active, and also varied to some extent between the different specimens.
The results in Table 3 are ranked according to intensity of average overall staining of the cornea, being greatest for albumin and least for $\alpha-2$ macroglobulin. The density of staining did not appear to depend on whether formol-saline or Carnoy's was used for fixation. With each antibody the staining was most concentrated in the periphery of the anterior stroma of the cornea. The high density in this region, closest to the limbal vessels, was particularly noticeable in the case of fibrinogen and $\alpha-2$ macroglobulin and to a lesser extent for transferrin and $\mathrm{C}_{3}$. For $\alpha-2$ macroglobulin it was usually the only area showing any trace of stain. For albumin the staining was most dense at the periphery of the cornea, but at all depths, more centrally, the staining for albumin became concentrated anteriorly beneath Bowman's membrane and posteriorly beneath Descemet's. With all other antibodies the staining of the central stroma was fairly uniform for all depths.

It was noticeable that with antialbumin Bowman's membrane did not stain in the controls and appeared as a bright line (Fig. 5). Its peripheral termination was therefore easily visible in these sections, though it did take up some stain in the pathological cases. Antifibrinogen on the other hand gave a denser stain with Bowman's layer than any other part of the cornea, as though fibrinogen had a particular affinity for this membrane.

Case 2 differed from the other pathological specimens in that a whole anterior segment was available. With each of the antibodies the area of

Table 3 Results of reaction with immune sera

\begin{tabular}{|c|c|c|c|c|}
\hline \multirow[b]{2}{*}{ Anti-sera* against } & \multicolumn{3}{|c|}{ Controls } & \multirow[b]{2}{*}{ Pathological specimens } \\
\hline & Epithelium & Bowman's & $\begin{array}{l}\text { Concentrated in periphery } \\
\text { of stroma anteriorly }\end{array}$ & \\
\hline Albumin & ++ & 0 & + (also deep periphery) & $\begin{array}{l}\text { Droplets in zone of densest reaction in anterior } \\
\text { stroma; have stained borders }\end{array}$ \\
\hline IgG & \pm (basal cells) & + & \pm & $\begin{array}{l}\text { Droplets in zone of darkest reactivity. Staining } \\
\text { rims (Case 6) }\end{array}$ \\
\hline Transferrin & + & + & + & $\begin{array}{l}\text { Staining around droplets in Case 2. Suggestion of } \\
\text { staining rims (Case 6) }\end{array}$ \\
\hline Fibrinogen & + & $\therefore \quad:$ & $\cdots 4$ & $\begin{array}{l}\text { Staining not especially concentrated around } \\
\text { droplets }\end{array}$ \\
\hline $\operatorname{Ig} \mathbf{A}$ & $\stackrel{-i}{-}$ & $\therefore$ & \pm & $\begin{array}{l}\text { Concentration of antibody around droplets in } \\
\text { anterior stroma (Case 6); staining droplet rims }\end{array}$ \\
\hline Complement $\mathrm{C}_{3}$ & $\therefore$ & $\because$ & 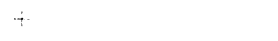 & Not usually concentrated around droplets \\
\hline $\operatorname{IgM}$ & Trace & \pm & \pm & Concentrated around droplets in one case \\
\hline$\alpha-2$ Macroglobulin & 0 & 0 & Trace & $\begin{array}{l}\text { Slight staining of peripheral [anterior stroma not } \\
\text { especially around droplets }\end{array}$ \\
\hline
\end{tabular}

*Anti-sera listed in order of average overall density of staining of corneal sections 


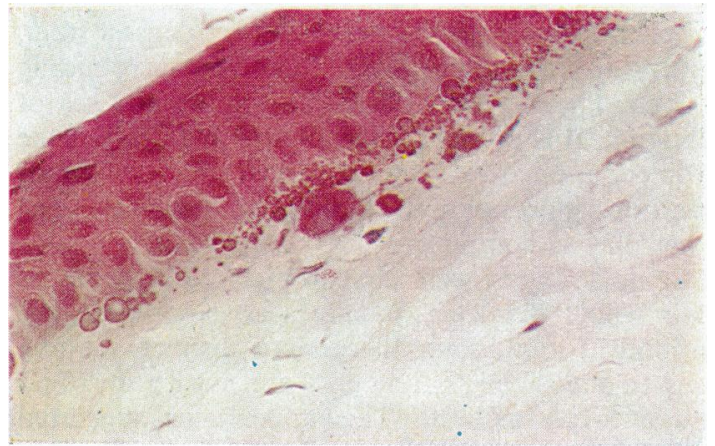

Fig. 6 Grade I (Case 2). Haematoxylin and eosin. Centres of droplets paler than periphery $(\times 340)$

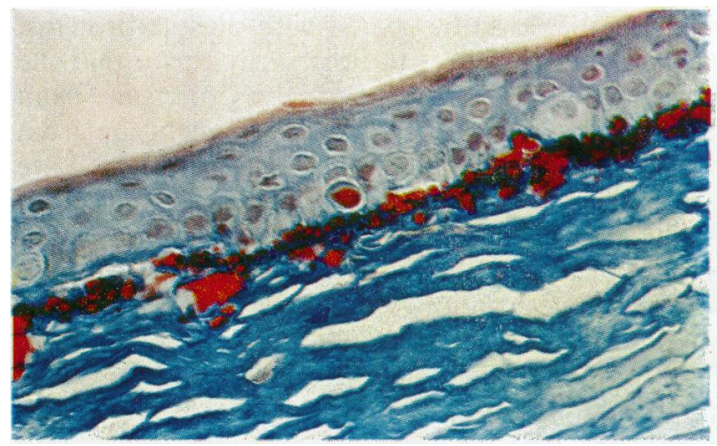

Fig. 8 Grade III (Case 5). Martius-scarlet-blue method for fibrin $(\times 170)$

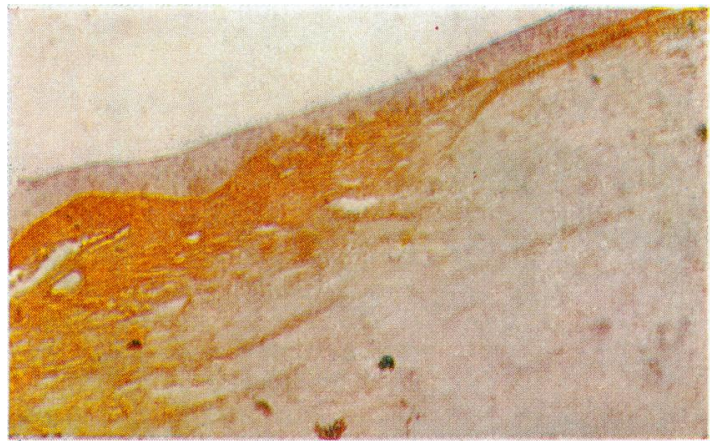

Fig. 10 Periphery of cornea of Case 2 (grade I keratopathy) reacted with antibody-enzyme ( $P A P)$ method for human transferrin. The antibody is concentrated in the anterior part of the pheriphery of the cornea. The few droplets in this section (pale blue) are in the most superficial layer of this zone $(\times 75)$

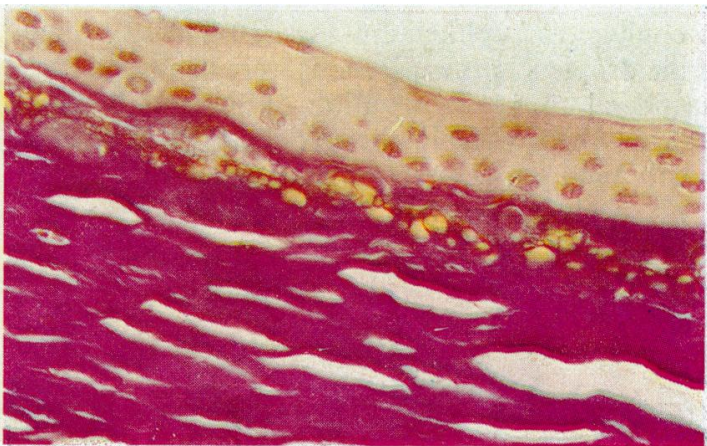

Fig. 7 Grade III (Case 5). Orcein-van Gieson. Droplets, pale yellow, did not stain for elastin $(\times 170)$

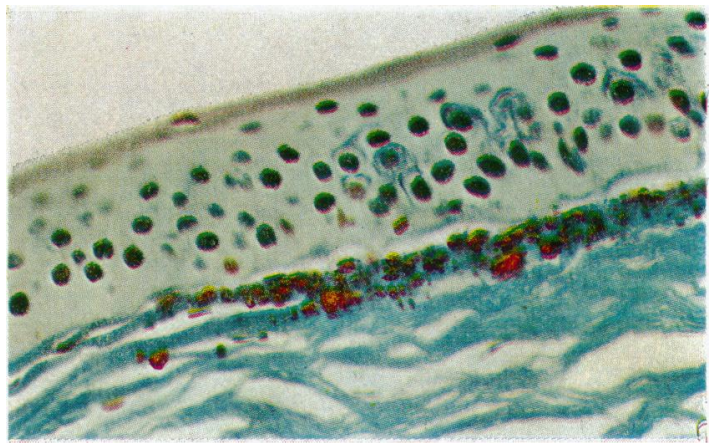

Fig. 9 Grade II (Case 8). Masson 44/41 method for old fibrin $(\times 340)$

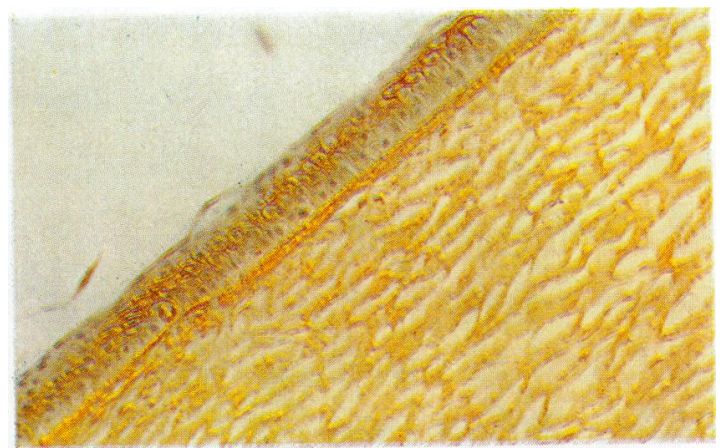

Fig. 11 More central portion of cornea of Case 2 (Grade I) reacted by $P A P$ method for $I g G$. The fine colourless droplets are in Bowman's membrane, which is also the most densely staining layer for antibody. This slide is from the same zone of cornea as Fig. $2(\times 115)$ 
densest staining in this specimen lay beneath the epithelium at the zone of transition from corneal to conjunctival epithelium (Figs. 10 and 12). Many of the droplets in these sections were deposited here, peripheral to the termination of Bowman's membrane. Others were in the periphery of Bowman's membrane itself (Fig. 11). Cases 6 and 9 (grade III

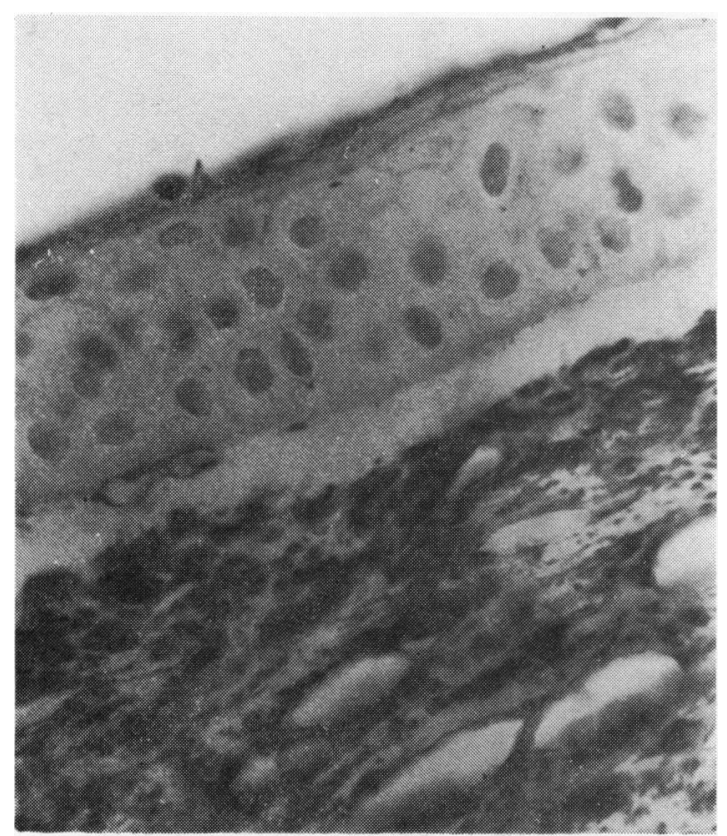

Fig. 5 Section of normal control cornea near periphery, reacted with antiserum to human serum albumin, followed by the antibody-enzyme (PAP) method. Albumin appears to be concentrated in the superficial stroma, while Bowman's membrane does not stain. (Magnification of negative $\times 160$, of this print $\times 470$.) keratopathy) had larger droplets more centrally situated. In all slides reacted with antialbumin the droplets were embedded in the zone of densest stain, appearing blue against the granular dark surrounding stroma. They appeared to be swimming in a sea of albumin. This concentration of staining around the droplets applied also to IgG and IgA (Fig. 11). It was not so pronounced with the antibodies to the other plasma components.

In no sections were the droplets stained across their whole diameter. In all cases exposed to the antibody for albumin there were distinct staining rims to the droplets, and in Case 6 with anti-IgG and anti-IgA as well. This appearance suggested that these proteins might be contributing to or were at least adhering to the outer shell of the droplets. There was also the suggestion of staining rims with antitransferrin.

Any aggregate of protein material in the cornea might be liable to be coated with plasma proteins. The staining rims do not necessarily prove that the spheroidal bodies are themselves derived from altered plasma proteins. The main conclusion from these tests is that these plasma constituents are present in the corneal stroma with a concentration gradient from the periphery to the centre, and that the droplets are spatially related to the areas of heaviest concentration, notably of albumin and to a less extent immunoglobulins and perhaps transferrin. It was also clear from Case 2 (grade I keratopathy), where the termination of Bowman's membrane was conspicuous in some slides, that droplets were deposited further peripherally and not restricted to Bowman's layer.

ELECTRON MICROSCOPY

Electron microscopy of the section fixed in formalin

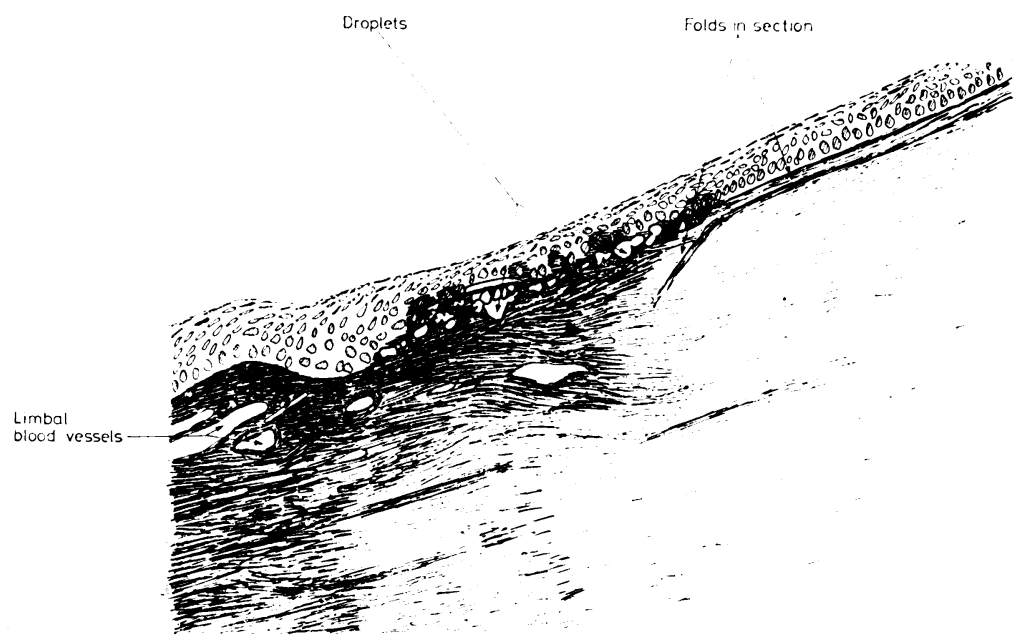

Fig. 12 Drawing of Fig. 10 (section of peripheral cornea of Case 2) showing position of droplets in relation to density of staining after reaction with antibody to human transferrin followed by the antibody-enzyme (PAP) method. Appearance with anti-IgA and anti-IgM similar but paler; with anti-IgG staining extended more uniformly into corneal stroma 
without any staining showed the droplets to be electron-dense, contrasting sharply with the surrounding stroma.

\section{Discussion}

Our results correspond in general with those of previous reports. Although the droplets stain with pyronin, they are not affected by RNA-ase. The Feulgen reaction has been universally negative in previous reports and in our tests. We do not think that nucleic acids are a main component of this material.

There is no evidence in any report or in these studies of a major carbohydrate component. Natural fluorescence in the case of amyloid is thought to reflect a high tryptophan and tyrosine content, and possibly an organised and orientated structure (Pearse, 1968). The explanation of the natural fluorescence of the corneal droplets from Labrador may be the same. However, the Congo red stain did not support the presence of amyloid, nor have previous electron micrographs (Johnson and Ghosh, 1975) given an impression of the fibrillar structure of amyloid.

The recent consensus has been to designate the spheroids as 'elastotic degeneration' or 'elastosis' (Brownstein et al., 1973; Rodrigues et al., 1975).

However, Garner and colleagues (1976) showed that spheroids in the cornea did not stain with either orcein or aldehyde fuchsin as if they had properties of elastic tissue, differing in this respect from elastotic material beneath pingueculae. On the other hand degenerated material from both sites stained with Verhoeff-van Gieson. This has now been confirmed in the tissue from Labrador (Fig. 7).

Gillman and his associates (1954) stressed the value of Mallory's phosphotungstic acid haematoxylin in distinguishing between 'fibrinoid', which stained purple as in our sections, and elastotic collagen (pale yellow or unstained). In a consideration of the class of protein which the droplets might contain the positive staining with Martius-scarletblue for a fibrin-like material becomes important. Lendrum et al. (1962) recommended this stain for the demonstration of fibrin; by staining both collagen and fibrin strong and different colours it shows their relationship with clarity (Fig. 8). In our sections there was no transitional zone between the surrounding collagen and the droplets.

However, the material is unlikely to consist predominantly of unaltered fibrin because of its consistent autofluorescence. Moreover, the immunoperoxidase method indicated that the droplets do not lie in the areas where a substance behaving antigenically as fibrinogen is most highly concen- trated. Fibrin is known to change its staining properties as it ages, but the Masson 44/41 method did not give the blue-black stain characteristic of old fibrin (Fig. 9).

The term 'fibrinoid' may be used to describe material derived from collagen in a rheumatic nodule. The keratopathy droplets are unlikely to be fibrinoid in this sense because of the demonstration in previous studies of the high content of tryptophan. So-called 'vascular fibrinoid', on the other hand, has been found to be composed largely of fibrin. Lendrum and associates (1962) pointed out that fibrinogen escaping from the lumen of an artery and precipitated intramurally as fibrin forms a spongework or filter which traps and concentrates other substances leaking out from plasma. The deposited admixtures of fibrin and other proteins in this site are thought to bring about slight differences in the staining reaction of the adulterated fibrin.

Staining reactions for fibrin are, according to Lendrum et al. (1962) dependent on the "fine structure' of the material rather than on a simple chemical reaction in the ordinary sense. This fine structure probably undergoes change with age. The droplets of climatic keratopathy are thought on clinical grounds to accumulate and increase in size very slowly over many years.

If the term fibrinoid is used to signify a material composed of plasma protein derivatives, including fibrin, then it might be applied to these droplets. From the staining reactions described above we should prefer at present to call the abnormal material of the droplets 'fibrinoid' rather than 'elastotic degeneration'.

\section{CLINICAL OBSERVATION}

Well-established clinical observations on the Labrador variety of this disease have not been sufficiently taken into account in discussions of the source and composition of the droplets. In his initial report Freedman (1965) clearly described the earliest stages, in which the droplets are first seen in the interpalpebral strip of exposed cornea at the temporal and nasal margins. The border of the zone of droplet deposition is separated from the nasal margin by a strip of clear cornea and is irregular, like a 'geographical coastline'. Towards the middle of the cornea the droplets become smaller and more sparsely arranged; only in the advanced stages do they reach the optical axis. Although the marginal strip is not completely free of droplets in every case, this general appearance (Fig. 13) has been confirmed by Johnson and Ghosh (1975) and Young and Finlay (1975). The clear zone is approximately $0.6 \mathrm{~mm}$ in width. Vascularisation 


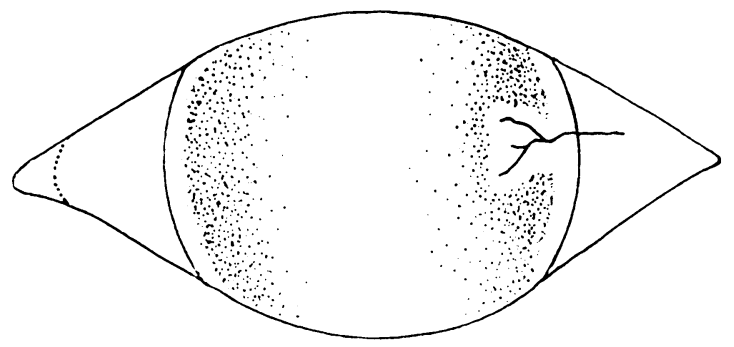

Fig. 13 Diagram of grade I Labrador keratopathy (spheroidal degeneration) to show marginal strip free of droplets and clear zone around an invading blood vessel

is not a feature of Labrador keratopathy, but occasionally, owing to incidental injury or disease, a blood vessel may be seen invading the cornea, as is represented on one side of Fig. 13. In an early grade of keratopathy there is characteristically a clear zone round such a vessel and its branches similar in width to the marginal clear zone.

All observers who have studied the disease in Labrador have no doubt that it is caused by exposure to a climatic factor. Demographic evidence (to be published separately) points to ultraviolet light as the essential agent. If the droplets were being formed from a structural component of the corneal stroma such as collagen, it would be expected that a uniform band of degeneration would extend across the whole width of the cornea even in the early stages. It might be expected that the same argument would apply to other theories of the origin of the material, such as from the turnover of the protein of the basement membrane or its derivation from disturbed keratocytes.

Another reason why the droplets cannot be formed from collagen without the accretion of extraneous protein material is their amino-acid composition. Type I collagen, of which the corneal stroma is composed, contains no tryptophan, cysteine, or cystine, very little tyrosine, and fairly small amounts of histidine. Methionine is present as less than 6 residues per 1000 (Lian et al., 1973). Tryptophan, tyrosine, and sulphur-containing aminoacids have all been demonstrated in considerable amounts in the droplets by other authors. The amino-acids which absorb ultraviolet light and undergo chemical degradation most easily are tryptophan and histidine, followed by cysteine, methionine, and tyrosine. As proteins go, therefore, collagen must be one of the most inert to ultraviolet. It is also extremely unlikely that changing the molecular configuration of collagen would make it dense enough, unstained, by electron micrography to be consistent with our result if it were the main component of the droplets.
PLASMA COMPONENTS IN THE CORNEA

There is good evidence that plasma constituents are normally present in the cornea as a result of diffusion from limbal vessels. Serum albumin appeared to be diffusing from the periphery of the cornea to the centre (Maurice and Watson, 1965) and also diffused out into the anterior chamber through the endothelium. It was present in the periphery of the cornea at 5 times the concentration in the centre. Immunoglobulins of classes IgG and IgA are also known from immunofluorescence studies to be present in the stroma of the human cornea although not conspicuous in Bowman's layer (Allansmith et al., 1973). In another study in which radioactively labelled IgG was injected into the periphery of the cornea the ratio of its concentration in the centre to that in the periphery varied from $1: 10.5$ at 2 days to $1: 2 \cdot 2$ at 8 days after injection (Stock and Aronson, 1970).

It is suggested from the results of this study that some of the plasma proteins during their diffusion through the cornea may be acted upon by ultraviolet light, which is absorbed by tryptophan in particular. The absorbed energy causes a primary reaction in the photosensitive amino-acids, which eventually results in precipitation of altered proteins in the stroma and particularly in Bowman's layer, possibly on a matrix of collagen fibrils, which may or may not themselves be altered. If this is what happens, the droplets might then be expected to contain a mixture of altered plasma constituents, including a proportion of fibrin. Different staining reactions, which at present appear contradictory, may reflect the diverse chemistry of the components of the spheroids. Our immunoperoxidase results suggest that, of the plasma constituents tested, albumin, immunoglobulins $\mathrm{G}$ and $\mathrm{A}$, and possibly transferrin, are present in the greatest concentrations in the zones where the deposits accumulate.

The cornea is the only part of the body where plasma proteins are exposed directly to light while diffusing across a tissue which is normally devoid of blood vessels. Under climatic conditions where snow blindness and inflammation of the eyes are almost constant it is also likely that the limbal vessels may leak more plasma constituents than usual.

We have noted that plasma proteins such as albumin and IgG are normally present in greater concentration in the periphery than the centre of the cornea, so that the build-up of altered protein might be expected to be greatest in the periphery of the interpalpebral strip. The corneal margin, which is usually free of droplets in early keratopathy, could be interpreted in one of three ways:

(1) The rate of diffusion adjacent to the limbus may be too great for the plasma proteins to be significantly 
acted upon by light until they have travelled a measurable distance from the limbal vessels.

(2) Alternatively, protein which has undergone the initial stages of transformation may be reabsorbed from this zone before it can be precipitated.

(3) It is also possible that the rather clear-cut outer edge of the area of droplet deposition may coincide with the peripheral termination of Bowman's membrane. Unless it could be shown, however, that Bowman's layer was destroyed round an invading blood vessel, the clear zones observed round such vessels argue against this third explanation. In addition, some droplets were seen by the immunoperoxidase method to be present in an area peripheral to the clear-cut termination of Bowman's layer, even in grade I, and are evidently not dependent on some physical property of this membrane in order to accumulate.

The idea that the abnormal spheroidal deposits are formed from plasma constituents present in the cornea and subconjunctival tissue under normal conditions is attractive in that it offers explanations of how similar material could also be laid down beneath the conjunctiva and in the cornea in a variety of intraocular diseases, and with advancing age, as well as under the influence of external climatic factors.

We thank Mr A. J. Bron, Professor J. O'D. McGee, and Dr J. McAvoy for their advice, and the staff of the Nuffield Laboratory of Ophthalmology for constructive discussion. We are grateful for the expert assistance of Mr J. Burns, Mr A. Chaplin, $\mathrm{Mr}$ D. Jerome, and Mr A. Buchan.

Publication was assisted by the Newfoundland Centre for Research in Labrador.

This investigation was supported in part by a grant from the E. A. Baker Fund of the Canadian National Institute for the Blind.

\section{References}

Allansmith, M. R., Whitney, C. R., McClellan, B. H., and Newman, L. P. (1973). Immunoglobulins in the human eye. Location, type and amount. Archives of Ophthalmology, 89, 36-45.

Brownstein, S., Rodrigues, M. M., Fine, B. S., and Albert, E. N. (1973). The elastotic nature of hyaline corneal deposits. A histochemical, fluorescent and electron microscopic examination. American Journal of Ophthalmology, 75, 799-809.

Burns, J. (1975). Background staining and sensitivity of the unlabelled antibody-enzyme (PAP) method. Comparison with the peroxidase labelled antibody sandwich method using formalin fixed paraffin embedded material. Histochemistry, 43, 291-294.

Christensen, G. R. (1973). Proteinaceous corneal degeneration. A histochemical study. Archives of Ophthalmology, 89, 30-32.

Culling, C. F. A. (1974). Handbook of Histopathological and
Histochemical Techniques, 3rd Edition, Butterworths: London.

Cursino, J. W., and Fine, B. S. (1976). A histologic study of calcific and non-calcific band keratopathies. American Journal of Ophthalmology, 82, 395-404.

D'Alena, P., and Wood, I. S. (1972). Labrador keratopathy: A microscopic study. American Journal of Ophthalmology, 74, 430-435.

Etzine, S., and Kaufmann, J. C. E. (1964). Band-shaped nodular dystrophy of the cornea. American Journal of Ophthalmology, 57, 760-763.

Fraunfelder, F. T., Hanna, C., and Parker, J. M. (1972). Spheroid degeneration of the cornea and conjunctiva. 1. Clinical course and characteristics. American Journal of Ophthalmology, 74, 821-828.

Freedman, A. (1965). Labrador Keratopathy. Archives of Ophthalmology, 74, 198-202.

Freedman, A. (1973a). Climatic droplet keratopathy. 1. Clinical aspects. Archives of Ophthalmology, 89, 193-197.

Freedman, A. (1973b). Labrador Keratopathy and related diseases. Canadian Journal of Ophthalmology, 8, 286-290.

Garner, A. (1970). Keratinoid corneal degeneration. British Journal of Ophthalmology, 54, 769-780.

Garner, A., Morgan, G., and Tripathi, R. C. (1973). Climatic Droplet Keratopathy. 2. Pathologic findings, Archives of Ophthalmology, 89, 198-204.

Garner, A., Fraunfelder, F. T., Barras, T. C., and Hinzpeter, E. N. (1976). Spheroidal degeneration of cornea and conjunctiva. British Journal of Ophthalmology, 60, 473-478.

Gillan, J. G. (1970). The cornea in Canada's Northland. Canadian Journal of Ophthalmology, 5, 146-151.

Gillman, T., Penn, J., Bronks, D., and Roux, M. (1954). Abnormal elastic fibers. Archives of Pathology, 59, 733-749.

Hanna, C., and Fraunfelder, F. T. (1972). Spheroid degeneration of the cornea and conjunctiva. 2. Pathology. American Journal of Ophthalmology, 74, 829-839.

Johnson, G. J., and Ghosh, M. (1975). Labrador Keratopathy: Clinical and pathological findings. Canadian Journal of Ophthalmology, 10, 119-135.

Klintworth, G. (1972). Chronic Actinic Keratopathy-a condition associated with conjunctival elastosis (pingueculae) and typified by characteristic extracellular concretions. American Journal of Pathology, 67, 327-348.

Lendrum, A. C., Fraser, D. S., Slidders, W., and Henderson, R. (1962). Studies on the character and staining of fibrin. Journal of Clinical Pathology, 15, 401-413.

Lian, J. B., Morris, S., Faris, B., Albright, J., and Franzblau, C. (1973). The effects of acetic acid and pepsin on the crosslinkages and ultrastructure of corneal collagen. Chimica et Biophysica Acta, 328, 193-204.

MacConaill, M. A., and Gurr, E. (1964). The histological properties of rhodanile blue. Irish Journal of Medical Science, 6, 243-250.

Maurice, D. M., and Watson, P. G. (1965). The distribution and movement of serum albumin in the cornea. Experimental Eye Research, 4, 355-363.

Pearse, A. G. E. (1968). Histochemistry, 3rd edition, Churchill: London.

Rodrigues, M. M., Laibson, P. R., and Weinreb, S. (1975). Corneal elastosis. Appearance of band-like keratopathy and spheroidal degeneration. Archives of Ophthalmology, 93, 111-114.

Stock, E., and Aronson, S. (1970). Corneal immune globulin distribution. Archives of Ophthalmology, 84, 355-359.

Wyatt, H. (1973). Corneal disease in the Canadian North. Canadian Journal of Ophthalmology, 8, 298-305.

Young, J. D. H., and Finlay, R. D. (1975). Primary spheroidal degeneration of the cornea in Labrador and Northern Newfoundland. American Journal of Ophthalmology, 79, 129-134. 